\title{
Rapid increase in the incidence of type 1 diabetes in Polish children from 1989 to 2004, and predictions for 2010 to 2025
}

\author{
P. Jarosz-Chobot $\cdot$ J. Polanska $\cdot$ A. Szadkowska $\cdot$ A. Kretowski $\cdot$ \\ E. Bandurska-Stankiewicz • M. Ciechanowska • G. Deja • M. Mysliwiec • \\ J. Peczynska • J. Rutkowska • A. Sobel-Maruniak • P. Fichna • A. Chobot • M. Rewers
}

Received: 25 April 2010 / Accepted: 23 September 2010 /Published online: 17 December 2010

(C) The Author(s) 2010. This article is published with open access at Springerlink.com

\begin{abstract}
Aims/hypothesis We analysed the temporal changes in the incidence of childhood type 1 diabetes and its demographic determinants in Poland from 1989 to 2004, validating the model with data from 1970 to 1989 . We also estimated a predictive model of the trends in childhood diabetes incidence for the near future.

Methods Children under 15 years with newly diagnosed type 1 diabetes mellitus and drawn from seven regional registries in Poland were ascertained prospectively using the Epidemiology and Prevention of Diabetes study (EURODIAB) criteria. The type 1 diabetes incidence rates
\end{abstract}

P. Jarosz-Chobot $(\bowtie) \cdot$ G. Deja

Department of Pediatrics,

Endocrinology and Diabetes,

Medical University of Silesia,

Medykow 16 Str.,

40-752 Katowice, Poland

e-mail: pjarosz-chobot@sum.edu.pl

J. Polanska

System Engineering Group,

The Silesian University of Technology,

Gliwice, Poland

A. Szadkowska

Department of Pediatrics, Oncology, Hematology and Diabetes,

Medical University of Lodz,

Lodz, Poland

A. Kretowski $\cdot$ J. Peczynska

Department of Endocrinology,

Diabetology and Internal Medicine,

Medical University of Bialystok,

Bialystok, Poland

E. Bandurska-Stankiewicz $\cdot$ J. Rutkowska

Endocrinology and Diabetology Ward, General District Hospital,

Olsztyn, Poland
(IRs) were analysed in dependency of age, sex, seasonality, geographical region and population density. Time trends in IR were modelled using several approaches.

Results The average incidence, standardised by age and sex, for 1989 to 2004 was 10.2 per 100,000 persons per year and increased from 5.4 to 17.7. No difference was found between boys and girls, or between urban and rural regions. In children above 4 years, IR was significantly higher in the population of northern Poland than in that of the country's southern part, as well as in the autumn-winter season, this finding being independent of child sex. Based on the trend model obtained, almost 1,600 Polish children

M. Ciechanowska

Department of Pediatric Endocrinology,

Polish-American Children Hospital,

Cracow, Poland

M. Mysliwiec

Department of Pediatrics, Oncology,

Hematology and Endocrinology, Medical University of Gdansk,

Gdansk, Poland

A. Sobel-Maruniak

Provincial Hospital No. 2,

Rzeszow, Poland

P. Fichna

Department of Endocrinology and Metabolism,

Poznan University of Medical Sciences,

Poznan, Poland

A. Chobot

Clinical Hospital No. 1,

Zabrze, Poland

M. Rewers

Division of Endocrinology, Metabolism and Diabetes,

Department of Medicine, University of Colorado,

Denver, CO, USA 
aged 0 to 14 years are expected to develop type 1 diabetes in 2010 , rising to more than 4,800 in 2025 . The estimates suggest at least a fourfold increase of IR between 2005 and 2025 , with the highest dynamics of this increment in younger children.

Conclusions/interpretation These estimates show that Poland will have to face a twofold higher increase in childhood type 1 diabetes than predicted for the whole European population. The dramatic increase could have real downstream effects on Poland's healthcare system.

Keywords Children · Epidemiology · Incidence rate

Seasonality. Type 1 diabetes

$\begin{array}{ll}\text { Abbreviations } & \\ \text { AIC } & \text { Akaike's information criterion } \\ \text { DIAMOND } & \begin{array}{l}\text { Diabetes Mondiale Project } \\ \text { EURODIAB }\end{array} \\ \begin{array}{l}\text { Epidemiology and Prevention of Diabetes } \\ \text { study }\end{array} \\ \text { IR } & \text { Incidence rate }\end{array}$

\section{Introduction}

The incidence of type 1 diabetes in children has been increasing by $3 \%$ to $5 \%$ per year worldwide since the 1960 s [1-4]. The environmental factors responsible for this epidemic remain unknown, but some evidence suggests that the highest increase is observed in countries undergoing rapid 'westernisation' [4]. Some of the strongest evidence for this secular increase in childhood diabetes has come from Poland [5-8]. In the 1990s, Poland experienced unprecedented socioeconomic transformations that culminated with the country's accession to the European Union in 2004. Against this background, we analysed the temporal changes in the incidence of childhood type 1 diabetes and its demographic determinants in Poland from 1989 to 2004, validating the model with data from 1970 to 1989 . In addition, a predictive model was developed to estimate the trends in childhood diabetes incidence for the near future.

\section{Methods}

Children with type 1 diabetes who had been diagnosed under the age of 15 years were identified prospectively using the Epidemiology and Prevention of Diabetes study (EURODIAB) criteria [9]. Data were collected by seven regional registries in Poland, between 1989 and 2004. The registries (Łódzkie, Małopolskie, Podlasie, Pomorskie, Silesia, Warmia-Mazury and Podkarpackie regions) cover approximately $35 \%$ of the Polish population. The data were collected from two independent sources: outpatient diabetic clinics and hospitals. In Poland every child diagnosed with type 1 diabetes is obliged to remain under the care of diabetic clinics within the public national healthcare system.

The population data were obtained from the country's Central Statistical Office (http://www.stat.gov.pl, accessed 10 March 2010). Type 1 diabetes incidence rates (IRs) and $95 \%$ CIs were estimated per 100,000 persons per year, among all children aged between 0 and 14 years, and in three age subgroups: 0 to 4,5 to 9 and 10 to 14 years old. The IRs were standardised by age and sex to the population of Poland in 2005.

Study of the IR was also performed according to sex, geographic region (southern vs northern Poland) and population density. The following regions were classified as belonging to northern Poland: Podlasie, Pomorskie and Warmia-Mazury, with the others constituting the southern Poland group. Regions defined as urban, with a population density higher than 120 people per $\mathrm{km}^{2}$, included Łódzkie, Małopolskie, Pomorskie and Silesia; the others were regarded as rural (Fig. 1).

Time trends in the IR of type 1 diabetes among children under 15 years of age up to 2025 were modelled using several approaches, from univariate linear models through multivariate linear models to generalised additive models with interactions of higher order [10]. Akaike's information

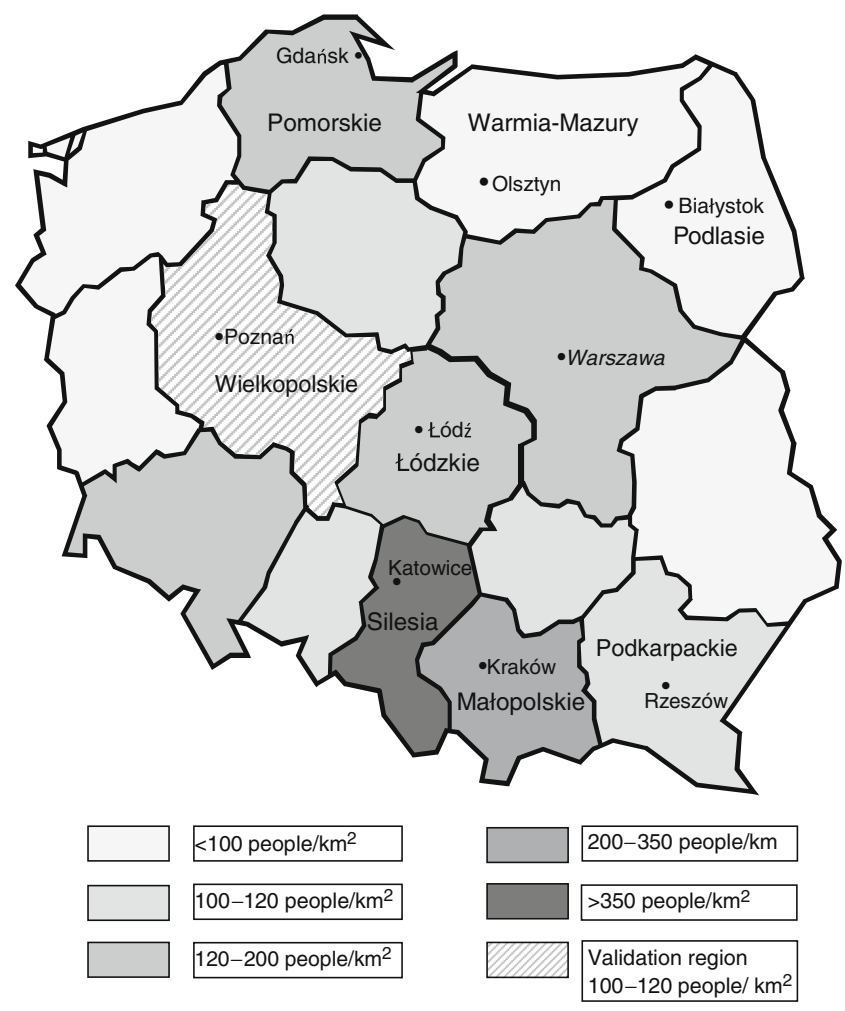

Fig. 1 The regions of Poland under investigation, with location and population density 
criterion (AIC), together with the test of relative fit, was used for model selection. Incidence data for 1970 to 1989 from Wielkopolskie and for 2005 to 2006 from Lódzkie were used to additionally validate the final model.

The seasonality of type 1 diabetes incidence throughout the year was evaluated using the Rayleigh test.

All statistical analysis was done in the Institute of Automatic Control, The Silesian University of Technology, Gliwice, Poland.

\section{Results}

Incidence rate and seasonality The primary data on the incidence of type 1 diabetes among children aged 0 to 14 years included 4,268 cases (2,230 boys, 2,038 girls). The average incidence, standardised for age and sex, for 1989 to 2004 was 10.2 per 100,000 persons per year $(95 \%$ CI 8.70-11.87). Between 1989 and 2004, the overall incidence increased more than threefold, from 5.4 to 17.7 per 100,000 persons per year. No significant difference was noticed between boys and girls, either for overall type 1 diabetes incidence, or in the three age subgroups over this period (Table 1).

In children aged above 4 years, IR was significantly higher in the population of northern Poland than in the south, this finding being irrespective of $\operatorname{sex}(p<0.05$; Table 2). No difference was found between urban and rural regions (Table 2).
A comparative age- and sex-stratified analysis of seasonality in type 1 diabetes incidence was performed (Fig. 2). A significant increase in type 1 diabetes incidence among children above 4 years of age was observed in the autumnwinter season $(p=0.1373$ for age group $0-4$ years, $p<$ 0.000001 for age groups 5-9 and 10-14 years). However, no statistical difference was found between boys and girls $(p>0.05)$.

Trend models Selection of the trend model of type 1 diabetes IR was done using the stepwise procedure, where several models were sequentially fitted to the data and the successive choices depended on the obtained quality of fit. Incidence of type 1 diabetes was assumed to follow the Poisson model. Two procedures were used to evaluate quality of fit: (1) the forward procedure with AIC criterion; and (2) the test of relative fit [10]. The starting step for the model selection procedure was construction of univariate linear models within different sex and age subgroups. Results of their fit to data are shown in Table 1. The dynamics of the increase of annual IR are described by the value in the slope coefficient. Based on the values in Table 1, the increase in annual IR is highest in the age stratum 5 to 9 years, this being independent of sex.

As seen from Table 1, the value of the slope coefficient significantly depends on the age group. This observation suggests that the dynamics of the IR increase depend on multiple variables, so in the next step, several multivariate generalised models were constructed [10] containing the

Table 1 Incidence rate in time line

\begin{tabular}{|c|c|c|c|c|c|c|c|c|c|}
\hline \multirow[t]{2}{*}{ Age group by sex } & \multicolumn{2}{|c|}{ 1989-2004 } & \multicolumn{2}{|c|}{1989} & \multicolumn{2}{|l|}{2004} & \multicolumn{3}{|c|}{ Time trend, linear model } \\
\hline & $\mathrm{IR}^{\mathrm{a}}$ & $95 \% \mathrm{CI}$ & $\mathrm{IR}^{\mathrm{a}}$ & $95 \% \mathrm{CI}$ & $\mathrm{IR}^{\mathrm{a}}$ & $95 \% \mathrm{CI}$ & Slope & $95 \% \mathrm{CI}$ & $p$ value \\
\hline \multicolumn{10}{|l|}{ Boys (years) } \\
\hline $0-4$ & 6.8 & $5.6-8.2$ & 1.9 & $0.2-7.0$ & 9.8 & $4.7-18.2$ & 0.55 & $0.42-0.67$ & $<0.000001$ \\
\hline $5-9$ & 10.7 & $9.1-12.4$ & 6.3 & $2.4-13.4$ & 19.3 & $11.7-30.1$ & 0.88 & $0.67-1.08$ & $<0.000001$ \\
\hline $10-14$ & 12.8 & $11.1-14.7$ & 7.9 & $3.4-15.7$ & 21.5 & $13.4-32.8$ & 0.65 & $0.43-0.87$ & 0.000016 \\
\hline $0-14$ & 10.4 & $8.9-12.1$ & 5.6 & $3.2-9.3$ & 17.4 & $13.0-23.1$ & 0.69 & $0.56-0.82$ & $<0.000001$ \\
\hline \multicolumn{10}{|l|}{ Girls (years) } \\
\hline $0-4$ & 5.5 & $4.4-6.8$ & 3.1 & $0.7-8.9$ & 12.7 & $6.7-21.9$ & 0.54 & $0.36-0.72$ & 0.000015 \\
\hline $5-9$ & 11.2 & $9.6-12.9$ & 5.3 & $1.8-12.0$ & 22.7 & $14.3-34.1$ & 0.94 & $0.70-1.17$ & $<0.000001$ \\
\hline $10-14$ & 12.3 & $10.7-14.2$ & 6.3 & $2.4-13.5$ & 17.7 & $10.5-28.1$ & 0.66 & $0.43-0.89$ & 0.000024 \\
\hline $0-14$ & 10.0 & $8.5-11.7$ & 5.1 & $2.8-8.5$ & 17.8 & $13.4-23.5$ & 0.71 & $0.57-0.86$ & $<0.000001$ \\
\hline \multicolumn{10}{|c|}{ Boys and girls (years) } \\
\hline $0-4$ & 6.2 & $5.0-7.5$ & 2.5 & $0.8-5.8$ & 11.2 & $7.1-16.9$ & 0.54 & $0.44-0.64$ & $<0.000001$ \\
\hline $5-9$ & 10.9 & $9.4-12.6$ & 5.8 & $2.9-10.2$ & 21.0 & $15.1-28.4$ & 0.91 & $0.75-1.08$ & $<0.000001$ \\
\hline $10-14$ & 12.6 & $10.9-14.4$ & 7.2 & $3.9-11.9$ & 19.7 & $14.0-26.9$ & 0.66 & $0.52-0.80$ & $<0.000001$ \\
\hline $0-14$ & 10.2 & $8.7-11.9$ & 5.4 & $2.6-9.4$ & 17.7 & $12.0-23.9$ & 0.69 & $0.59-0.79$ & $<0.000001$ \\
\hline
\end{tabular}

${ }^{a}$ Per 100,000 persons per year 
Table 2 Incidence rate in different geographical and demographical regions

\begin{tabular}{|c|c|c|c|c|c|c|c|c|c|c|c|c|}
\hline \multirow{2}{*}{$\begin{array}{l}\text { Age group by } \\
\text { sex }\end{array}$} & \multicolumn{2}{|c|}{ Northern Poland } & \multicolumn{2}{|c|}{ Southern Poland } & \multicolumn{2}{|c|}{ North vs south } & \multicolumn{2}{|c|}{ Urban regions } & \multicolumn{2}{|c|}{ Rural regions } & \multicolumn{2}{|c|}{ Urban vs rural } \\
\hline & $I^{\mathrm{a}}$ & $95 \% \mathrm{CI}$ & $\mathrm{IR}^{\mathrm{a}}$ & $95 \% \mathrm{CI}$ & OR & $95 \% \mathrm{CI}$ & $\mathrm{IR}^{\mathrm{a}}$ & $95 \% \mathrm{CI}$ & $\mathrm{IR}^{\mathrm{a}}$ & $95 \% \mathrm{CI}$ & OR & $95 \% \mathrm{CI}$ \\
\hline \multicolumn{13}{|l|}{ Boys (years) } \\
\hline $0-4$ & 6.7 & $5.5-8.0$ & 6.8 & $5.6-8.2$ & 0.98 & $0.80-1.20$ & 6.9 & $5.7-8.3$ & 6.3 & $5.1-7.6$ & 1.12 & $0.89-1.40$ \\
\hline $5-9$ & 12.1 & $10.5-13.9$ & 9.9 & $8.4-11.6$ & 1.23 & $1.06-1.42$ & 10.5 & $9.0-12.3$ & 10.9 & $9.4-12.7$ & 0.96 & $0.82-1.13$ \\
\hline $10-14$ & 14.0 & $12.3-16.0$ & 12.2 & $10.5-14.0$ & 1.15 & $1.01-1.30$ & 12.8 & $11.1-14.7$ & 12.7 & $11.0-14.6$ & 1.00 & $0.87-1.15$ \\
\hline $5-14$ & 13.2 & $11.5-15.1$ & 11.2 & $9.6-12.9$ & 1.18 & $1.07-1.30$ & 11.8 & $10.2-13.6$ & 11.9 & $10.3-13.8$ & 0.99 & $0.89-1.10$ \\
\hline $0-14$ & 11.3 & $9.7-13.1$ & 9.9 & $8.4-11.6$ & 1.14 & $1.04-1.24$ & 10.4 & $8.9-12.1$ & 10.3 & $8.8-12.0$ & 1.01 & $0.92-1.12$ \\
\hline \multicolumn{13}{|l|}{ Girls (years) } \\
\hline $0-4$ & 6.1 & $5.0-7.4$ & 5.2 & $4.2-6.4$ & 1.18 & $0.94-1.49$ & 5.3 & $4.2-6.5$ & 6.1 & $5.0-7.4$ & 0.90 & $0.70-1.15$ \\
\hline $5-9$ & 12.4 & $10.7-14.2$ & 10.6 & $9.1-12.3$ & 1.18 & $1.02-1.37$ & 11.6 & $10.0-13.4$ & 10.1 & $8.6-11.7$ & 1.15 & $0.98-1.37$ \\
\hline $10-14$ & 14.1 & $12.4-16.1$ & 11.4 & $9.9-13.2$ & 1.24 & $1.09-1.41$ & 12.3 & $10.6-14.1$ & 12.4 & $10.8-14.3$ & 0.99 & $0.85-1.14$ \\
\hline $5-14$ & 13.4 & $11.6-15.3$ & 11.1 & $9.5-12.8$ & 1.21 & $1.10-1.34$ & 12.0 & $10.3-13.8$ & 11.4 & $9.8-13.1$ & 1.06 & $0.95-1.18$ \\
\hline $0-14$ & 11.3 & $9.7-13.0$ & 9.4 & $8.0-11.0$ & 1.20 & $1.09-1.31$ & 10.1 & $8.6-11.7$ & 9.9 & $8.4-11.5$ & 1.03 & $0.94-1.14$ \\
\hline \multicolumn{13}{|c|}{ Boys and girls (years) } \\
\hline $0-4$ & 6.4 & $5.2-7.8$ & 6.0 & $4.9-7.3$ & 1.06 & $0.91-1.24$ & 6.1 & $5.0-7.5$ & 6.2 & $5.0-7.5$ & 1.01 & $0.86-1.20$ \\
\hline $5-9$ & 12.3 & $10.6-14.1$ & 10.2 & $8.8-11.9$ & 1.20 & $1.08-1.33$ & 11.0 & $9.5-12.8$ & 10.5 & $9.0-12.2$ & 1.05 & $0.94-1.18$ \\
\hline $10-14$ & 14.1 & $12.3-16.1$ & 11.8 & $10.2-13.6$ & 1.19 & $1.09-1.30$ & 12.6 & $10.9-14.4$ & 12.6 & $10.9-14.5$ & 0.99 & $0.90-1.10$ \\
\hline $5-14$ & 13.3 & $11.5-15.2$ & 11.1 & $9.6-12.9$ & 1.20 & $1.12-1.28$ & 11.9 & $10.3-13.7$ & 11.7 & $10.0-13.4$ & 1.02 & $0.95-1.10$ \\
\hline $0-14$ & 11.3 & $9.7-13.0$ & 9.7 & $8.2-11.3$ & 1.17 & $1.10-1.24$ & 10.3 & $8.8-12.0$ & 10.0 & $8.5-11.7$ & 1.02 & $0.96-1.10$ \\
\hline
\end{tabular}

${ }^{\text {a }}$ Per 100,000 persons per year

explaining variables year, age and sex, as well as some possible interaction terms of these explaining variables. Results of fitting this model to the data are presented in Table 3 (base model section). This section shows several variants of multivariate generalised models, together with values of the two criteria describing the quality of fit, residual variance and AIC. On the basis of both criteria of model fit, the best (final) model is the one listed at the bottom of the base model section. Along with the explain- ing variables year, age group and sex, which influence the dynamics of IR, this model includes two interaction components to the trend. The first interaction component is related to different dynamics in age groups (year:age). This component captures the negative interaction between calendar year and age group, reflecting the annual decrease in IR among children above 9 years old, relative to the IR among the younger ones. The second component is associated with the age and sex interaction (age:sex). This
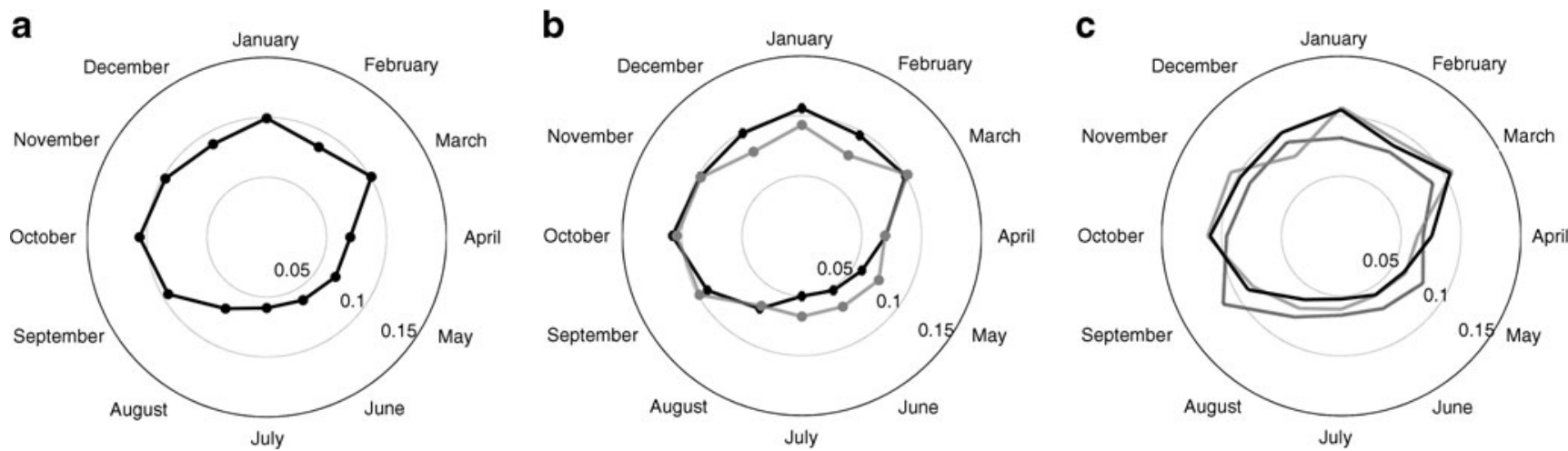

Fig. 2 Circular distribution of type 1 diabetes mellitus incidence. a Overall seasonality in boys and girls aged 0 to 14 years, standardised for age and sex. b Sex-dependent seasonality, boys (black symbols/ line) vs girls (grey symbols/line). c Age-dependent seasonality by age group. Black dashed line, age group 0-4 years; grey line, age group
5-9 years; black continuous line, age group 10-14 years. The radius length $(\mathbf{a}-\mathbf{c})$ represents the percentage of cases diagnosed on average each month. Irregularity in shape, i.e. departures from circularity, demonstrates the seasonality of incidence 
Table 3 General additive models for time trend of type 1 diabetes mellitus incidence

\begin{tabular}{|c|c|c|c|}
\hline Models & $\begin{array}{l}\text { Residual } \\
\text { deviance }\end{array}$ & AIC & $p$ value $^{\mathrm{a}}$ \\
\hline \multicolumn{4}{|l|}{ Base model } \\
\hline Null model & $2,883.4$ & & \\
\hline Year $^{\dagger}$ & $1,872.8$ & $2,487.6$ & $<0.000001$ \\
\hline Age* & $1,343.2$ & $1,960.0$ & $<0.000001$ \\
\hline Age $^{*}+$ Year $^{\dagger}$ & 332.59 & 951.34 & $<0.000001$ \\
\hline 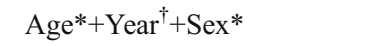 & 315.23 & 935.97 & 0.000031 \\
\hline 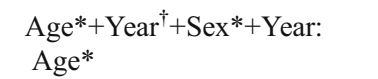 & 259.78 & 884.53 & $<0.000001$ \\
\hline $\begin{array}{l}\text { Age*+Year } \dagger+\text { Sex}_{*+\text { Year: }} \\
\text { Age*+Age:Sex* }\end{array}$ & 239.51 & 868.26 & 0.000040 \\
\hline \multicolumn{4}{|c|}{ Base model + geographical region ${ }^{\mathrm{b}}$, final model } \\
\hline Null model & $6,396.12$ & & \\
\hline $\begin{array}{l}\text { Age }^{*+Y} \text { Year } \dagger+\text {Sex}^{*+}+\text { Year: } \\
\text { Age*+Age:Sex } \\
*+\text { Region*c }\end{array}$ & 953.7 & 2202.8 & $<0.000001$ \\
\hline \multicolumn{4}{|c|}{ Base model + population density ${ }^{\mathrm{d}}$, final model } \\
\hline Null model & $6,280.3$ & & \\
\hline $\begin{array}{l}\text { Age*+Year } \dagger+\text { Sex+Year: } \\
\text { Age*+Age:Sex*+Area*e }\end{array}$ & $1,153.1$ & $2,407.9$ & $<0.000001$ \\
\hline
\end{tabular}

The AIC and $p$ values $\left(^{\mathrm{a}}\right.$ ) from the test of relative fit (compared with the best model in the previous step) are presented for model selection

${ }^{\mathrm{a}}$ Test of relative fit

${ }^{\mathrm{b}}$ Region: north, south

c + Year:Region*+Age:Region*

${ }^{\mathrm{d}}$ Area: urban, rural

e +Year:Area*+Year:Sex+Age:Area*+Area:Sex*+Age:Area:Sex* +Year:Area:Sex*

*Significant components $(p<0.05)$

${ }^{\dagger}$ Significant non-linear components $(p<0.05)$

interaction component corrects for age depending on sex where the lower IR among the youngest girls compared with the youngest boys becomes similar to the IR among boys within the older children's group (Fig. 3b).

Figure 4 presents the standardised IR in the overall Polish population between 0 and 14 years of age during the observation period, as well as the best-fitting time trend. Figure $3 \mathrm{a}, \mathrm{b}$ demonstrates the results for sex and age groups.

Validation of the final model was done with the use of independent registers. The observed number of new cases in the Łódzkie region during 2005 and 2006 was similar to that predicted from the generalised time trend model, i.e. 141.3 vs 153 , error $7.7 \%$. The prediction error was on average equal to the $22.2 \%$ (from $0.15 \%$ to $59.2 \%$ ) for incidence in the Wielkopolskie register from 1970 to 1989 [5].

To perform comparative analysis between northern and southern Poland, as well as between urban and rural areas, two more models were elaborated, one including dependence on the geographical region, the other including dependence on the area (rural or urban), as indicated (Table 3). According to these models, IRs depend on the geographical location of the regions and are significantly higher in northern Poland. Interaction components correct for these differences, showing the IR is growing faster in southern Poland in general. The increase is the highest among children aged 5 to 9 years (Fig. 3c).

Although the final model in the comparison of urban with rural regions includes a set of significant interaction terms, their effects cancel each other out, and at the moment no differences in type 1 diabetes incidence are detectable between urban and rural regions. However, according to the model established in this study, a slightly higher rise in IR can be expected in urban areas (Fig. 3d).

Based on the elaborated general additive modelling model and assuming a constant population size at the level of 2005, almost 1,600 Polish children aged 0 to 14 years are expected to develop type 1 diabetes in 2010, while more than 4,800 will be diagnosed in 2025. During the next 15 years, from 2010 to 2025 , we expect 46,633 children to be diagnosed with type 1 diabetes in Poland, a figure significantly higher than the predictions given by the linear model, i.e. 24,472 new cases (Fig. 5).

\section{Discussion}

The global increase in the incidence of type 1 diabetes in children and adolescents is widely recognised, although considerable variability has been observed among countries $[11,12]$. Scandinavia has one of the highest IRs of childhood diabetes, although variability is high, both between and even within different countries [4]. Increasingly often, moreover, type 1 diabetes is being observed in patients with low genetic susceptibility [13]. Environmental factors therefore seem to represent a major trigger, initiating the disease by their sequential or simultaneous influence and/or due to lack of protective environmental agents [14-18].

Epidemiological studies conducted in the 1980s and early 1990s, such as EURODIAB and the Diabetes Mondiale Project (DIAMOND), ranked Poland among countries of very low type 1 diabetes incidence, with approximately 6.6 cases per 100,000 persons per year [2, 3, 11]. Current studies $[8,19]$ indicate considerable change in this classification, grouping Poland with countries that have medium type 1 diabetes incidence, i.e. above 15 cases per 100,000 persons per year.

The dynamic increase in new cases of type 1 diabetes in Central and Eastern Europe has been reported recently by various investigator teams $[2,4,20-22]$. Thus in the EURODIAB study [4], which covered 1989 to 2003, 
Fig. 3 Estimates of IR. a Estimates, standardised IR, dependent on age groups. b Estimated IR, dependent on sex and age, geographical regions and population density groups. Age groups indicated as above (a); sex-dependent lines are labelled accordingly.

c IR dependent on geographical location. Grey line, trend for northern Poland; black line, trend for southern Poland. d Estimated IR for dependence on population density. Grey line, urban areas; black line, rural regions
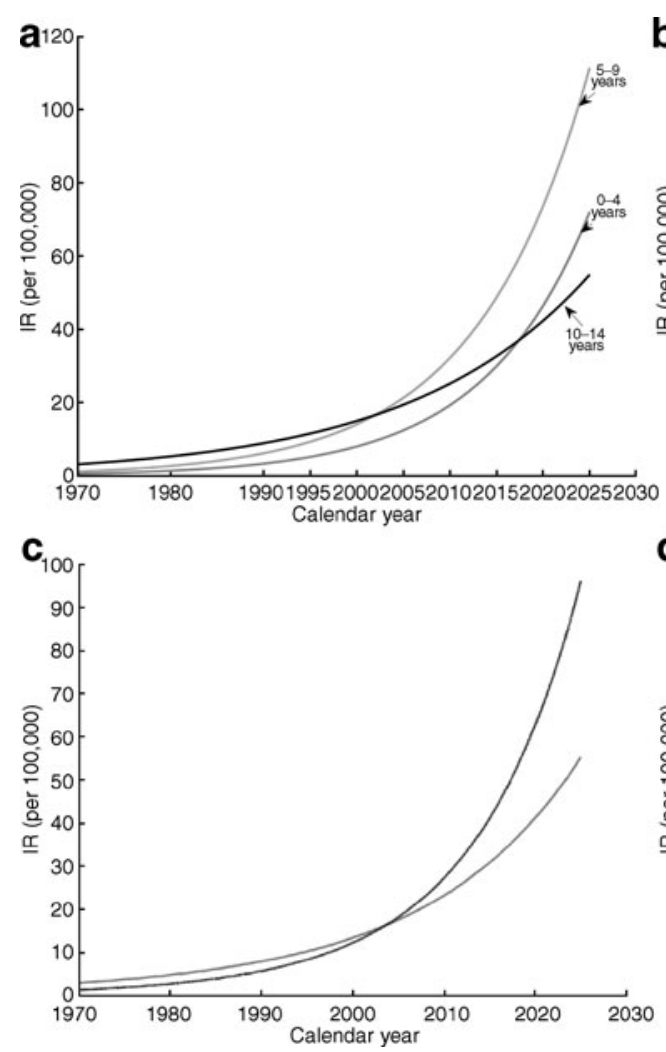
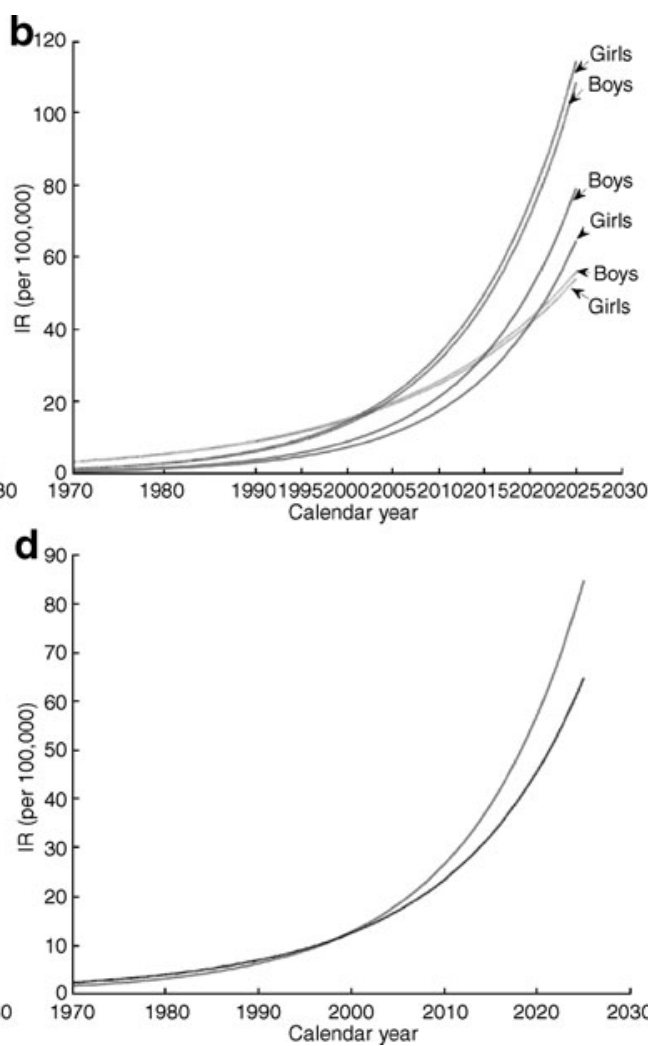

Poland was represented by the Silesian region, with a mean maximal increase in IR of $9.3 \%$ per year. Similar results were found for other Eastern European states: Romania (8.4\% increase), the Czech Republic (6.7\% increase) and Slovakia (5.1\% increase in diabetes incidence). By contrast, countries traditionally experiencing high type 1 diabetes incidence, such as Finland, Sweden and Norway, showed more modest increases of only $2.7 \%, 3.3 \%$ and $1.3 \%$, respectively.

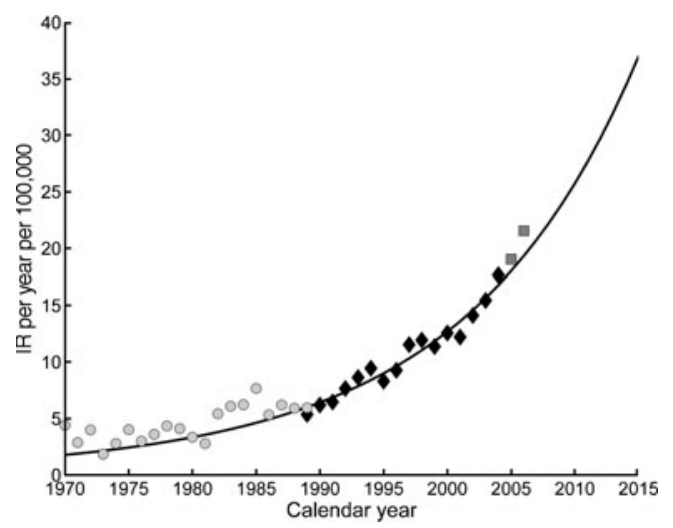

Fig. 4 Generalised additive model for time trend of type 1 diabetes mellitus incidence, standardised for age and sex, in Poland, 1970 to 2004. Black diamonds, observed cases; black continuous line, generalised additive modelling prediction; light grey circles, observed cases, validation data from Wielkopolskie region; dark grey squares, observed cases, validation data from Łódzkie region
This dramatic increase of new cases in the countries named could be associated with their rapid adoption of a westernised lifestyle after the socioeconomic transformations seen since the early 1990s [22, 23]. The most important factors connected with this process are, in our opinion: the wide availability of pre-processed food, the popularisation of fast-food and lifestyle-related changes in leisure activities, e.g. computer/internet and media player use instead of natural physical activity. These and similar factors have probably caused the twofold increase in prevalence of overweight and obesity among Polish

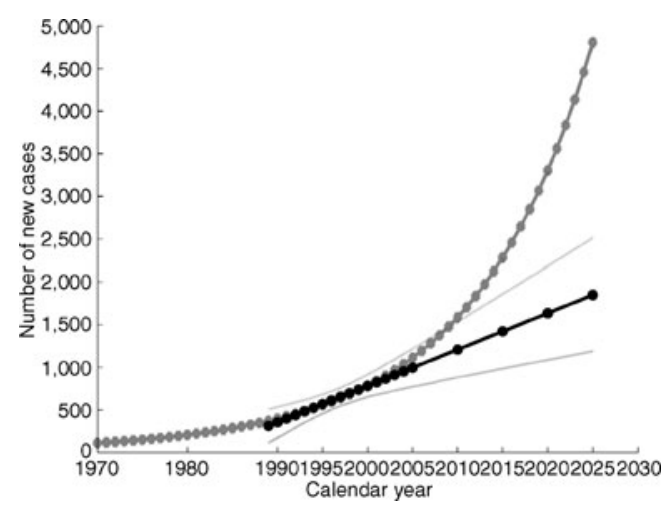

Fig. 5 Prediction of type 1 diabetes mellitus new cases, standardised by age and sex, in Poland, obtained by generalised additive modelling and linear trend models. Grey symbols, predictions obtained with generalised additive modelling; black symbols, predictions obtained by univariate linear model and respective 95\% CIs (continuous grey lines) 
children [24]. The predicted incidence of type 1 diabetes in Polish children and adolescents in the next 15 years is alarming. A validated statistical model enabled us to reliably predict that from 2010 to 2025 the number of new cases would reach 46,600 , with an evident downward shift in the age of onset.

The model established in this study confirms previous observations of a most remarkable rise in childhood type 1 diabetes incidence among the youngest age groups $[25,26]$. Thus the number of children who will not even remember their pre-diabetes life, without insulin dependence, is rising. Likewise, the impact of prognostic factors that strongly contribute to chronic diabetic complications, e.g. disease duration and its influence on the psychosocial development of a child and his/her family, is being extended.

In some regions, sex-related differences have been reported in selected age subgroups [27, 28]. Our analysis of the Polish population revealed a similar distribution of new cases in both sexes, with no changes forecast for the following years. The north-south gradient in type 1 diabetes incidence, with a higher disease frequency in the northern regions, has been previously described $[4,12,21]$. This type of incidence distribution was also observed by us in Poland. However, future predictions indicate that an inverse trend may emerge in the coming years. This apparent inversion might be explained by a rapid increase in type 1 diabetes incidence across the whole country. Another factor worth considering is the relatively small distance between the studied regions, $400 \mathrm{~km}$ on average.

While progressive urbanisation might be a contributory factor to the increased type 1 diabetes incidence, the data on this subject remain inconsistent $[27,28]$. Our analysis did not reveal significant differences between urban and rural areas, although a slightly higher incidence was noted in areas characterised by more dense populations, this being particularly visible in the proposed predictive model.

The estimate of the increase in type 1 diabetes does not seem to be influenced by changes in identification of cases. This has remained high and stable throughout the past five decades, due to the Polish healthcare system. All children with diabetes remain under the care of paediatric diabetes centres.

A recent report by the DIAMOND group on seasonality in type 1 diabetes incidence demonstrates that, in some regions of the world ( $40 \%$ of all participating centres), winter or summer peaks are discernible, depending on the geographic coordinates of the country [29]. These relations seem particularly true for countries more distant from the equator, countries with higher IR and among older children. In our study, apart from the youngest subgroup, the seasonality of type 1 diabetes incidence is clearly visible, with the highest emergence of new cases during the autumn and winter months. Plausible explanations for this phenomenon usually focus on the higher incidence of viral and bacterial infections at this time of the year $[16,17]$. In contrast, infectious morbidity in the youngest children is less season-dependent, which might be reflected in this long-term observation. Another explanation of the seasonal rise in type 1 diabetes may be related to the increased physical activity and lack of school stress during the summer holiday [29, 30].

Our study has several limitations. It covers only $35 \%$ of the childhood diabetes population, the result of Poland not having a national diabetes register. Our regional registers include only patients up to 14 years of age, because the healthcare system allows patients from the age of 16 years to decide whether to stay in paediatric care or move to adult care. Additionally, only a limited number of functional dependences could be investigated during model building and the obtained estimates should be treated with some caution. It seems reasonable that the process of IR increase will not follow exponential-like growth, but will reach some saturation level in the future. To be able to detect that level, the data must include the symptoms of such a process. However, the incidence of type 1 diabetes in Poland is still growing rapidly, thereby making such detection impossible. The prediction obtained for 2025 classes Poland with countries that have an IR equal to 75 cases per 100,000 persons per year, a value comparable to the predictions for Scandinavian countries [31]. As predictions made more than a few years ahead can prove to be very inaccurate, it should be kept in mind that the conclusion on the possible rapid rise of type 1 diabetes mellitus cases is not definite.

During the past 15 years the incidence of childhood type 1 diabetes in Poland has increased threefold, with a predicted additional at least fourfold increase from 2005 to 2025 , with the highest dynamics of this increment in the youngest age group. These estimates show that Poland will have to face a twofold higher increase in childhood type 1 diabetes than that predicted for the whole European population. The EURODIAB data published in 2009 forecast only a less than twofold increase in new cases (until 2020), with the same incidence trend among younger and very young children [4].

While 12,465 cases were diagnosed in Poland from 1989 to 2004 , more than 46,600 cases are expected in the following 16 years. The burden of childhood diabetes will therefore increase dramatically, with clear downstream effects on the country's healthcare system.

Acknowledgements We would like to thank H. Dziatkowiak for her deep involvement in keeping the regional Malopolska diabetes register and the EURODIAB Study Group for the continuous encouragement for the regional Silesian register since 1998. The work was supported in part by KBN grant number NN519 579938. Parts of this study were presented at the EASD Vienna and International Society for Paediatric and Adolescent Diabetes Lubljana meetings in 2009. 
Duality of interest The authors declare that there is no duality of interest associated with this manuscript.

Open Access This article is distributed under the terms of the Creative Commons Attribution Noncommercial License which permits any noncommercial use, distribution and reproduction in any medium, provided the original author(s) and source are credited

\section{References}

1. Diabetes Epidemiology Research International Group (1990) Secular trends in incidence of childhood IDDM in 10 countries. Diabetes 39:858-864

2. The Diamond Project Group (2006) Incidence and trends of childhood T1DM worldwide 1990-1999. Diabet Med 23:857-866

3. EURODIAB ACE Study Group (2000) Variation and trends in incidence of childhood diabetes in Europe. Lancet 335:873-876

4. Patterson CC, Dahlquist GG, Gyürüs E et al (2009) Incidence trends for childhood type 1 diabetes in Europe during 1989-2003 and predicted new cases 2005-20: a multicentre prospective registration study. Lancet 373:2027-2033

5. Rewers M, LaPorte RE, Walczak M, Dmochowski K, Bogaczynska E (1987) Apparent epidemic of insulin-dependent diabetes mellitus in Midwestern Poland. Diabetes 36:106-113

6. Jarosz-Chobot P, Otto-Buczkowska E, Koehler B, Matlakiewicz E, Green A (2000) Increased trend of type 1 diabetes mellitus in children's population ( $0-14$ years) in Upper Silesia region (Poland). Med Sci Monit 6:573-580

7. Kretowski A, Kowalska I, Pęczyńska J, Urban M, Green A, Kinalska I (2001) The large increase of type 1diabetes mellitus in Poland. Diabetologia 44(Suppl 3):B48-B50

8. Bandurska-Stankiewicz E, Rutkowska J, Klonowska B, Charemska D, Przybylowicz K (2006) Incidence of type 1 diabetes mellitus in age group 0-14 in Warmia and Mazury Region between 1994-2003. Exp Clin Diabetol 5:242-247

9. Green A, Gale EAM, Patterson CC (1992) Incidence of childhoodonset insulin-dependent diabetes mellitus: the EURODIAB ACE Study. Lancet 339:905-909

10. Hastie TJ, Tibshirani RJ (1990) Generalized additive models. Chapman and Hall, London

11. Green A, Patterson CC, EURODIAB TIGER Study Group (2001) Europe and diabetes. Trends in the incidence of childhood-onset diabetes in Europe 1989-1998. Diabetologia 44(Suppl 3):B3-B8

12. Devendra D, Liu E, Eisenbarth GS (2004) Type 1 diabetes: recent developments. BMJ 328:750-754

13. Fourlanos S, Varney MD, Tait BD et al (2008) Rising incidence of type 1 diabetes is accounted for by cases with lower-risk human leukocyte antigen genotypes. Diab Care 31:1546-1549

14. Dalquist G, Patterson C, Soltesz G (1999) Perinatal risk factors for childhood type 1 diabetes in Europe. Diab Care 22:1698-1702
15. Akerblom H, Vaarala O, Hyoty H, Ilonen J, Knip M (2002) Environmental factors in the ethiology of type 1 diabetes. Am J Med Genet 115:18-29

16. The EURODIAB Substudy 2 Study Group (2000) Infections and vaccinations as risk factors for childhood type 1 diabetes mellitus: a multicentre case control investigation. Diabetologia 43:47-53

17. The Teddy Study Group (2007) The Environmental Determinants of Diabetes in the Young (TEDDY) Study: study design. Pediatr Diab 8:286-298

18. TRIGR Study Group (2007) Study design of the Trial to Reduce IDDM in the Genetically at Risk (TRIGR). Pediatr Diab 8:117135

19. Jarosz-Chobot P, Deja G, Polanska J (2010) Epidemiology of type 1 diabetes among Silesian children aged 0-14, 1989-2005. Acta Diabetol 47:29-33

20. International Diabetes Federation (2009) IDF diabetes atlas. The global burden. Available from: www.diabetesatlas.org/content/ international-diabetes-federation

21. Libman IM, LaPorte RE (2005) Changing trends in epidemiology of type 1 diabetes mellitus throughout the world: how far have we come and where do we go from here. Pediatr Diab 6:119-121

22. Jarosz-Chobot P, Polanska J, Polanski A (2008) Does socialeconomical transformation influence the incidence of type 1 diabetes mellitus? A Polish example. Pediatr Diab 3:202-207

23. Haynes A, Bulsara MK, Bower C, Codde JP, Jones TW, Davis EA (2006) Independent effects of socioeconomic status and place of residance on the incidence of childhood type 1 diabetes in Western Australia. Pediatr Diab 7:94-100

24. Chrzanowska M, Koziel S, Ulijaszek SJ (2007) Changes in BMI and the prevalence of overweight and obesity in children and adolescents in Cracow, Poland, 1971-2000. Econ Hum Biol $5: 370-378$

25. Karvonen M, Pitkaniemi J et al (1999) The onset age of type 1 diabetes mellitus in Finnish children has become younger. Diab Care 22:1066-1070

26. Kyvik KO, Nystrom L, Gorus F et al (2004) The epidemiology of type 1 diabetes mellitus is not the same in young adults as in children. Diabetologia 47:377-384

27. Soltesz G, Patterson CC, Dahlquist G, on behalf of EURODIAB Study Group (2007) Worldwide childhood type 1 diabetes incidence - what can we learn from epidemiology? Pediatr Diab 8(Suppl 6):6-14

28. Soltesz G (2003) Diabetes in the young: a pediatric and epidemiological perspective. Diabetologia 46:447-454

29. Moltchanova EV, Schreirer N, Lammi N (2009) Seasonal variation of diagnosis of type 1 diabetes mellitus in children worldwide. Diabet Med 26:673-678

30. Wilkin TJ (2001) The accelerator hypothesis: weight gain as the missing link between type 1 and type 2 diabetes. Diabetologia 44:914-922

31. Harjutsalo V, Sjöberg L, Tuomilehto J (2008) Time trends in the incidence of type 1 diabetes in Finnish children: a cohort study. Lancet 371:1777-1782 